$0.15 \mathrm{mg}$ twice or thrice daily for seven days; blood was collected every day before the morning dose of the drug and on the fourth and seventh days blood samples were also taken at hourly intervals for $3 \mathrm{~h}$ after the first daily dose of clonidine. No significant increase in serum GH was detected during the acute studies, though minor elevations occurred in three male subjects after intravenous clonidine (net increase ranging between 2.3 and $4.3 \mu \mathrm{g} \mathrm{l}$ ) and in two of them after oral administration of the drug (net increase $2 \cdot 4-4 \cdot 6 \mu \mathrm{g} 1$ ). During the seven days of treatinent only one man and one woman patient exhibited isolated increases in serum GH concentration of minor magnitude (less than $5 \mu \mathrm{g} 1)$.

Though we have no personal data on the effects of $x$-adrenoceptor agonists on $\mathrm{GH}$ secretion in normal subjects, Lal et al, ${ }^{1}$ using clonidine, and Drs L ancranjan and Marbach, using BS 100-141, found that they caused an increase in serum $\mathrm{GH}$ levels in healthy male volunteers. Clonidine was also found to stimulate $\mathrm{GH}$ secretion in adult male rhesus monkeys" and rats." Though aging has been associated with reduced spontaneous and stimulated GH release, ${ }^{4}$ Drs Lancranjan and Marbach found no increase in plasma $\mathrm{GH}$ levels in young hypertensive patients under chronic treatment with BS 100-141. Thereforc the possibility cannot be excluded that the failure of $x$-adrenoceptor agonists to stimulate GH secretion in hypertensive subjects migh be due to some alteration in $x$-adrenoceptors associated with the hypertensive state.

CARLO FERRAR GiampaOlo Testor Roberto CaLDara CristiaNo Barbier 2nd Department of Medicine. Farebenefratelli Hospital. Milan, Italy

' I.al, S, et al, Fournal of (ilinical Endocrinology and Metabolism, 1975, 41, 827 hambers, J W, and Brown, (; M, Endocrinology. Ruch, wi, 1976,

${ }^{3}$ Ruch, W, et al, Experientia, 1976, 32,529.

27, 225.
Bazzarre, T I, et al, in I'roceedings of the IIIrd Inter national Symposium on (irowth Hormone and Müller. Amsterdam, Excepta Medica, 1976.

\section{Hospital inpatient provision for patients} with dementia

Sir,-Dr David Jolley (21 May, p 1335) doubts the DHSS plan of 2.5-3.0 beds for elderly demented for every 1000 people over 65 because this estimate is based only on the number of demented patients in mental hospitals in 1971. He also wants to include those in geriatric beds and Part III accommodation, making 5 beds per 1000. But has $\mathrm{Dr}$ Jolley included elderly demented patients in the wards of general hospitals? There are usually two or three in my wards waiting almost indefinitely for transfer.

J H BARON

St Charles Hospital

London $\mathrm{W} 10$

\section{Wound sepsis: effect of incidental appendicectomy}

SIR,-In a series of 224 patients we found that removal of a normal appendix together with the gall bladder caused a higher rate of wound sepsis than cholecystectomy alone in patients not protected by cephaloridine. We have analysed a consecutive series of 131 patients undergoing elective truncal vagotomy and pyloroplasty for peptic ulcer. All other gastric operations were excluded. Sixty-one patients had ragotomy and pyloroplasty and 70 incidental appendicectomy as well. The primary wound sepsis rates were $334\left(8.8^{\circ}\right.$. and $230\left(6.7^{\circ}\right)$ respectively in patients protected by cephaloridine and $627\left(22 \cdot 2^{\circ}{ }_{0}\right)$ and $1040\left(25 \cdot 0^{\circ}\right)$ in the others. There are no significant differences between the rates with and without appendicectomy.

A V POLLOCK

carborough Hospital.

Scarborough

MARY EvaNS

Pollock, A V, and Evans, .1. British . Medical Fournal.
$1977,1,20$.

\section{Use of ritodrine in pregnant diabetics}

SIR,-Following several reports of the successful use of ritodrine in pregnant women the data sheet for ritodrine has been altered as Dr C J Chandler suggests (30 April, p 1159). It will now read as follows:

\section{Precantions}

(Paragraph 2) Although glucose and insulin profiles in normal pregnant women have been shown in controlled clinical trials not to alter under Yutopar therapy, it is recommended that in the diabetic patient monitoring of glucose levels be undertaken. \section{Duphar Laboratories I.td.}

T C G SMITH

\section{Lithium carbonate in schizoaffective states}

SIR,-I was interested to read about Dr W W Sargant's use of lithium carbonate in schizoaffective states (4 June, p 1470). At this unit there are two outpatients currently attending who suffer from recurring bouts of schizoaffective illness and for whom the use of lithium carbonate has been found to be of great help.

Case 1-An 18-year-old male patient who had his first attack at the age of 13. The clinical picture then was of very florid and bizarre delusions, with auditory hallucinations, thought disorder, and accompanied by great psychomotor activity. A diagnosis of schizophrenia was made and phenothiazine medication instituted. A further simila florid psychotic breakdown occurred two year later. Last vear while attending this unit and while still on a high level of long-acting phenothiazine medication he developed a third attack. It was ver interesting to observe how the attack developed He became more active, more restless, showed pressure of speech, and for the next 14 days he showed gross insomnia. All of these features were quite resistant to even high doses of phenothiazines. At the end of this period he showed tvpical acute schizophrenic picture with gros thought disorder, delusions, and hallucinations. However, when put on lithium carbonate he rapidly stabilised, and over the past eight month continuation of lithium carbonate along with small dose of phenothiazines has stabilised him so well that he is now in open employment for the first time in his life.

Case 2-A 28-year-old female patient who had five recurring schizoaffective attacks for 11 year resulting in 18 months of hospitalisation over this period of time. She too had been on a high level of long-acting phenothiazine medication, which on its own had failed utterly to prevent relapses, which, when they occurred, always presented clinically with excitement, ideas of reference, thought disorder, delusions, and hallucinations. Her last attack was ushered in by an acceleration of psychomotor activity accompanied by a sever insomnia state. After about 10 days she then began to express delusions of a religious and paranoid nature, showed ideas of reference, and had auditory hallucinations. In this state she too was quite unresponsive to phenothiazines. However, response to lithium carbonate was both rapid and sustained, and her progress in the nine months since then has been surprisingly good. She is rapidly discarding her "chronic patient" image and, as her parents report, "is returning to her old self."

The above cases are interesting for two reasons. One is the diagnostic one: schizoaffective illness is a definite clinical entity containing as it does features common to both schizophrenic and affective states. However, it is important to make the diagnosis accurately as otherwise the patient will usually be classified as schizophrenic and will therefore receive inadequate medication. In this regard there is a lot to be said for Ollerenshaw's' recommendation that acute schizophrenia should be regarded as simply a variant of the manic phase of manic-depressive illness. Secondly, and more intriguingly, what exactly is the role of sleep deprivation in these states? Could, for instance, severe sleep loss, as in the above two cases, be the missing ingredient which converts a manic state into an acute schizophrenic one? The role of sleep deprivation in producing psychiatric symptoms is not fully clear, but the kind of sleep loss in a manic state must surely be very considerable and perhaps nearer to being a total sleep loss state than that produced experimentally.

A J MCGFinis St John's Day Centre,
I Jublin

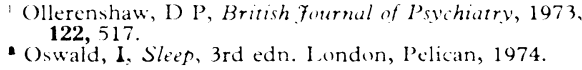

Ollerenshaw, D P, British Fournal of Psychiatry, 1973. $122,517$.

- Oswald, I, Sleep, 3rd edn. London, Pelican, 1974.

\section{Microsomal enzymes in malnutrition}

SIR,-We apologise for commenting so late on the interesting article by Dr K Krishnaswamy and Dr A N Naidu entitled "Microsomal enzymes in malnutrition as determined by plasma half life of antipyrine," (26 February p 538), but our personal half life for absorption of the $B M Y$ is currently prolonged. We believe that this article, quoted in vour recent leading article (21 May, p 1304), is somewhat misleading.

In the summary we read that "the half life of antipyrine was modified in undernourished subjects and those with nutritional oedema.' In the article, however, it is clearly shown that there is no difference in antipyrine half life between the group of undernourished subjects who were smokers (and exposed to pesticides and the appropriate control group of smokers. It is not possible to judge whether the half life of antipyrine was modified in those with nutritional oedema as we appear not to be told if this group (group 4) were smokers; the mean half life for group 4 was apparently longer, although no P value was given, than that for the smoking controls (group 2) but no different from that for the non-smoking controls (group 1).

Even if the half life of antipyrine were prolonged in patients with nutritional oedema when compared with the appropriate control subjects, this could at least partly result from a 
difference in volume of distribution of the drug rather than solely from a true difference in hepatic microsomal function. It is stated that some expansion of the extracellular fluid volume remained in the oedematous patients despite three days' treatment with frusemide, and this is confirmed by the lower estimated mean plasma antipyrine concentration at time zero in this group $(6 \cdot 18: \mathrm{mol} / 1$ compared with $6.44,6.39$, and $6.48: u \mathrm{~mol} / \mathrm{l}$ in groups $1-3$ respectively). Thus it is possible that there was a spuriously prolonged half life in the presence of a normal hepatic antipyrine clearance in these patients, and we feel that this possibility deserves fuller consideration.

Finally, we question the validity of administering to oedematous patients a dose of antipyrine calculated from the body weight.

IAN T GILMORE R P H THOMPSON

\section{St Thomas's Hospital,} London SE1

\section{Management of hypertension}

SIR,-Granted that blood pressure is not recorded as often as it might be, both in general practice and in hospital (see Dr R F Heller and Professor G Rose, 4 June, p 1441), we could at least publicise the reading once known. All printed hospital discharge and casualty notes as well as registrar's summaries should include a box for BP. Not only would this enter the GP's record folder, but it might also remind the GP of his obligation to include abnormal readings in his referral letters to hospitals.

RICHARD STONE

London W2

\section{Drug compliance in hypertensive patients}

SIR,-Drs A J Marshall and D W Barritt (14 May, p 1278) comment that it is appropriate to test carefully whether patients are more likely to take tablets prescribed only once daily than in daily divided doses and whether calendar packing is feasible and preferable. In their study of atenolol they failed to obtain consistent tablet taking for one-third of the time.

We studied 42 hypertensive patients for 16 weeks-four weeks on conventional oxprenolol three times daily, eight weeks on slow oxprenolol once daily, and a final four weeks back on conventional oxprenolol. Patients were assessed at two-weekly intervals. Conventional oxprenolol was dispensed loose in bottles and slow oxprenolol was dispensed in the manufacturer's calendar packs; a variable number of surplus tablets was supplied each time.

$70 \%$ of 39 patients took all their tablets, as judged by tablet counting, while on slow oxprenolol. Only three took less than $90 \%$; two took $86 \%$ and one $88^{\circ} \%$ of the correct dosage, one of these also complying poorly on conventional oxprenolol. Thus compliance was good on slow oxprenolol in $92^{\circ}{ }_{\circ}^{\circ}$ (36 of 39 patients). Two patients withdrew from the study shortly after starting on slow oxprenolol, owing to dizziness and abdominal distension respectively. One patient withdrew for domestic reasons. Thirty-three of 41 patients $(80 \%)$ preferred slow oxprenolol to conventional oxprenolol.
All patients found that the calendar pack was helpful, particularly in enabling them to determine whether or not they had taken their tablets.

As pointed out in your leading article (26 March, p 793) and by Marshall and Barritt, tablet counting may be misleading and may give an overestimate of compliance. Even allowing for this, however, it is probable that the majority of patients on slow oxprenolol exceeded the $80 \%$ value which may be designated as compliance. The full results of this study will be reported elsewhere.

David Persoff

St Andrew's Hospital,

London E3

\section{Learnt voluntary control of the heart}

SIR,-I was interested in your article on voluntary heart control (11 June, p 1491) because 50 years ago I discovered that I could make my pulse speed up and my pupils dilate while absolutely motionless, much to the amusement of some fellow undergraduates. I had completely forgotten about this but find I have retained the facility.

The technique of learning is rather like that for contracting individual muscles of the leg where one has to transfer a joint-movement volition to a relatively abstract muscular association. Pupil dilatation and heart acceleration were at first achieved by autoinduction of repressed excitement. This is associated with a sort of descending wave of excitement travelling down the body from beneath the sternum, and I suppose one developed a direct ability to provoke that without recourse to any of the original psychological process. I see your references date back to 1971 , but I had never heard of anything else of this nature until reading your leading article.

\section{J ShaCkLeton Bailey}

Moreton-in-Marsh

\section{Sulphinpyrazone in acute stuttering}

\section{hemiparesis}

SIR,-What does a physician do when confronted by a patient with an acute stuttering hemiparesis? An ischaemic process may be thought likely, but the retrospective diagnosis of transient ischaemia or of completed slowonset stroke must await the passage of time. The imminent danger of a complete disabling hemiplegia may prompt one to therapeutic intervention, but no treatment is established. Published controlled trials of anticoagulant therapy are not convincing of benefit ${ }^{12}$ and anticoagulant treatment of cerebral vascular disease is associated with a high risk of intracranial bleeding," " partly because cerebral haemorrhage or tumour cannot be excluded by clinical examination and routine investigations. On the basis that platelet thromboemboli play a role in cerebral ischaemia drugs affecting platelet function, such as sulphinpyrazone, have been studied in patients with transient ischaemic attacks with promising initial results. ${ }^{5}$ We wish to report a patient with an acute stuttering hemiparesis which resolved after initiation of sulphinpyrazone therapy.

A 67-year-old housewife was admitted to hospital six hours after the sudden onset of right- sided weakness involving the face, arm, and leg. The initial episode lasted $30 \mathrm{~min}$ and resolved completely, but weakness recurred one hour later and the patient experienced six episodes of similar duration on the day of admission, four of which were documented by physicians. On admission intermittent dysarthria, lower right facial weakness, and flaccid weakness of the right arm and leg were noted. The optic fundi were normal. An aortic systolic murmur was heard but there were no carotid bruits. Blood pressure on admission was $200 / 100 \mathrm{~mm} \mathrm{Hg}$, falling to $140 / 80 \mathrm{~mm} \mathrm{Hg}$. Investigations did not reveal any relevant pathology. Shortly after admission she was started on sulphinpyrazone $200 \mathrm{mg}$ thrice daily; $18 \mathrm{~h}$ later she had only mild subjective right-sided weakness, and by $36 \mathrm{~h}$ after admission she was asymptomatic. There was no recurrence of symptoms over the next seven days and she was discharged home on sulphinpyrazone. She was reviewed some six weeks after discharge and was still symptom-free.

Controlled trials of sulphinpyrazone in the management of patients with transient ischaemic attacks and of patients with reasonable recovery from a completed stroke are currently in progress. In addition, controlled trials of antiplatelet agents in patients with unstable cerebral ischaemia, such as we have described, would seem worth while despite the difficulties of definition and the relative rarity of such patients. To prevent completion of an evolving stroke would be desirable, as would early treatment of transient ischaemic attacks. In a recent community study the greatest risk of completed stroke was in the first month after development of transient ischaemic attacks. ${ }^{6}$ Experience with sulphinpyrazone so far suggests that it is a less hazardous treatment than anticoagulants or carotid artery surgery.

GORDON LOWE RAYMOND V JOHNSTON University Department of Medicine, Royal Infirmary, Glasgow

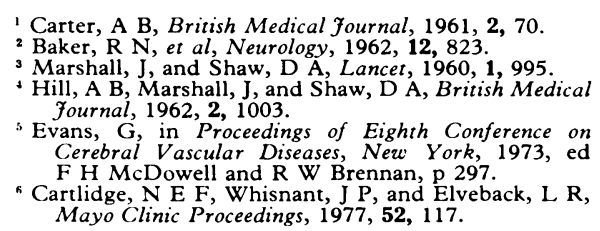

Colony-forming cells and myeloblasts in chronic granulocytic leukaemia

SIR,-The demonstration by Dr A J Barrett and his colleagues (14 May, p 1259) that a relationship exists between colony-forming cells (CFUc) and blast-cell numbers in the peripheral blood of a patient undergoing treatment with splenic irradiation for chronic granulocytic leukaemia (CGL) is of great interest because a relationship between myeloblasts and their presumed progenitor cell can be predicted on kinetic grounds. Their failure to demonstrate a relationship between CFUc and total leucocyte numbers must, however, be a temporary phenomenon reflecting an initially selective effect of splenic irradiation on immature granulocytes since we and others have demonstrated such a relationship in untreated patients, in busulphan-treated patients, and in a patient treated by long-term leucopheresis alone. ${ }^{1-4}$

In most patients with CGL whose leucocyte counts have been reduced or restored to normal during treatment with busulphan blast cells have disappeared from the blood and CFUc numbers are low (but not absent). Such a trend is seen also in Dr Barrett's radiotherapy-treated patient. This 